\title{
«Abracadabra» \\ in der Stiftsbibliothek
}

\section{Eberhard Wolff}

PD Dr. rer. soc., Redaktor Kultur, Geschichte, Gesellschaft

Der eindrucksvolle Barocksaal der St. Galler Stiftsbibliothek ist für sich schon ein touristischer Besuchermagnet (Abb. 1). Bis Anfang November dieses Jahres bietet der Saal für die (medizin-)historisch Interessierten noch ein Extra: «Abracadabra» heisst die Sommerausstellung der Bibliothek, in der es um die Medizin des Mittelalters geht. Die Ausstellungsmacher haben aus den kostbaren Handschriften-Beständen ihrer Bibliothek einige Schätze in die Vitrinen gelegt, in denen es um Medizinisches geht, insbesondere um die damals enge Verbindung von Medizin und Religion.

Wiborada (gestorben 926) etwa war eine gelehrte Einsiedlerin im St.Gallischen. Die Legende erzählt davon, wie sie vor und nach ihrem Tod kranke und verunfallte Menschen geheilt habe. Als erste Frau wurde Wiborada im Jahre 1047 von einem Papst heiliggesprochen. Die Ausstellung zeigt die reich illustrierte Handschrift eines St.Galler Bürgers mit Heiligenlegenden aus dem 15. Jahrhundert. In der Illustration (Abb. 2) heilt die heilige Wiborada einen Besessenen. Die Übergänge zwischen

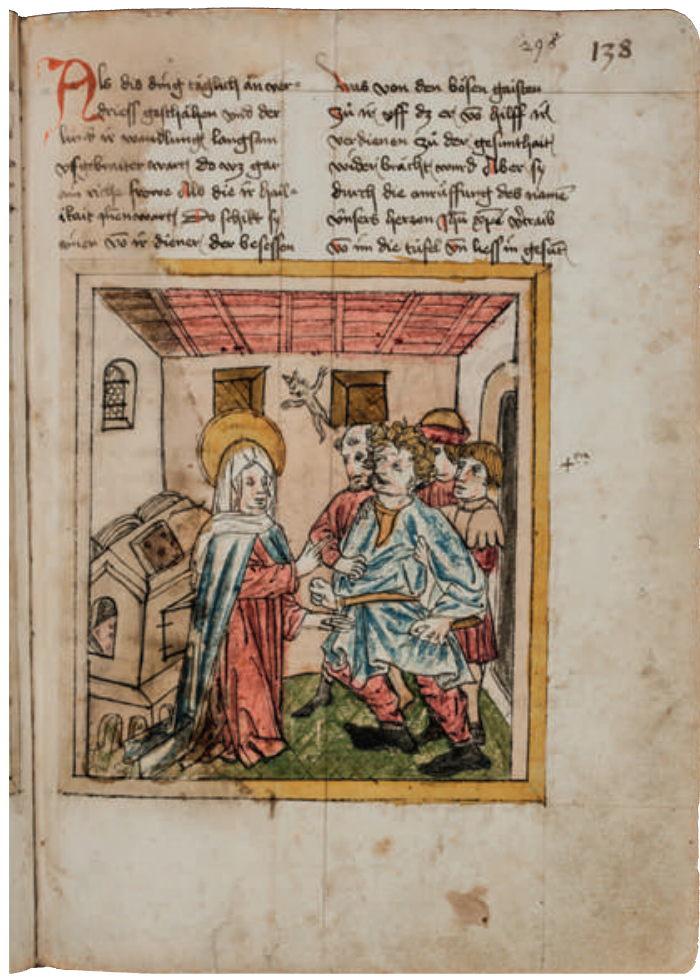

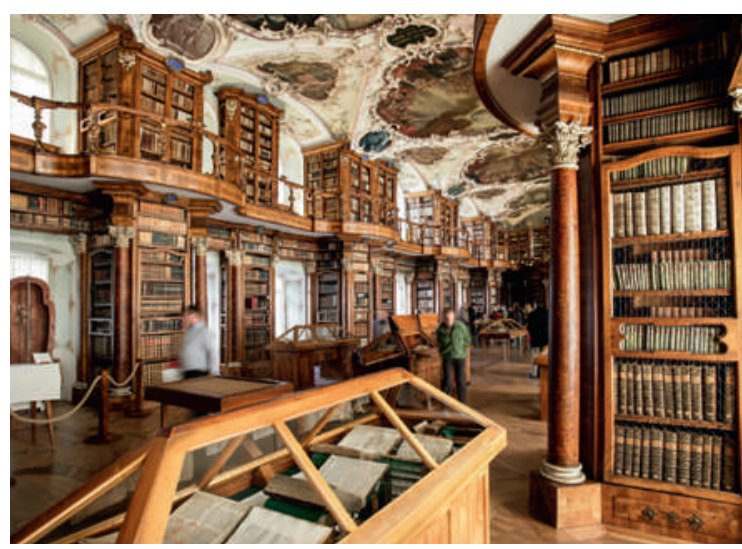

Abbildung 1: Der Barocksaal. (c) Stiftsbibliothek St. Gallen.

medizinischem und religiösem «Besessensein» waren fliessend.

Klöster waren im Mittelalter Angelpunkte medizinischer Praxis. Der St. Galler Klosterplan aus dem 9. Jahrhundert sieht für seine Zeit ausgiebige hospitalartige Infrastrukturen vor. Die Benediktinerregeln formulierten die Krankensorge als christliche Aufgabe.

In Klöstern wurden auch medizinische Texte, oft aus der Antike, abgeschrieben und verwahrt. Mit ihrem Titel "Abracadabra" verweist die Ausstellung auf zwei der ältesten erhaltenen Abschriften des "Liber medicinalis», das auf den antiken Arzt Quintus Serenus zurückgeht. Auch diese Kostbarkeiten aus dem 9. Jahrhundert zählen zu den St. Galler Bibliotheksbeständen. Darin findet sich eine Bauanleitung für ein «Schwundzauber»-Amulett. Es sollte vor einer Krankheit schützen, hinter der die heutige Malaria angenommen wird: Man schreibe das Wort "Abracadabra" mehrfach untereinander und lasse jedes Mal den letzten Buchstaben weg, bis nur noch das «A» übrig bleibt und ein auf der Spitze stehendes Dreieck entsteht. In der Klosterbibliothek ist somit eine der ältesten bekannten Überlieferungen des Wortes «Abracadabra» in Schriftform zu sehen.

\section{Abracadabra. Medizin im Mittelalter}

Sommerausstellung im Barocksaal der Stiftsbibliothek St. Gallen bis 6. November 2016

Katalog: 131 Seiten, vor Ort erhältlich

Mehr Informationen unter: www.stibi.ch 